\title{
NOVEL FERMENTATION PRODUCTS FROM STREPTOMYCES FRADIAE: X-RAY CRYSTAL STRUCTURE OF 5-O-MYCAROSYLTYLACTONE AND PROOF OF THE ABSOLUTE CONFIGURATION OF TYLOSIN
}

\author{
Noel D. Jones, Michael O. Chaney, Herbert A. Kirst, Gene M. Wild, \\ Richard H. Baltz, Robert L. Hamill and Jonathan W. Paschal \\ The Lilly Research Laboratories, Eli Lilly and Company \\ Indianapolis, Indiana, 46285 U.S.A.
}

(Received for publication December 14, 1981)

\begin{abstract}
5-O-Mycarosyltylactone has been isolated as a predominant factor from fermentation broths of a Streptomyces fradiae mutant. The relative configurations of mycarose and tylactone (protylonolide) have been determined by X-ray crystal structure analysis. Hydrolysis of 5-Omycarosyltylactone yielded (-)-tylactone and L-(-)-mycarose. Taken together, these two experiments establish the absolute configuration of (-)-tylactone. Bioconversion of (-)tylactone to tylosin by $t y l G$ mutants of $S$. fradiae proves the absolute configuration of tylosin. Physicochemical data for tylactone and a unique component piece of tylactone are also reported.
\end{abstract}

Two minor products, which lack antibacterial activity, were initially isolated from the fermentation broths of tylosin-producing strains of Streptomyces fradiae. More recently, these same two products have been obtained in much higher yield from fermentations of a $t y l B$ mutant strain of $S$. fradiae. ${ }^{1)}$ This mutant was blocked only in formation or addition of the amino sugar, mycaminose, to the 5-hydroxyl group of the lactone ring and accumulated tylactone (or protylonolide ${ }^{2)}$ ), (1), and a shunt product, 5-O-mycarcisyltylactone (2). Recently these same two products have been found by ŌMURA and coworkers ${ }^{2,3)}$.

The structures of $\mathbf{1}$ and $\mathbf{2}$ have been deduced from a detailed analysis of physicochemical data (Table 1), including proton NMR spectra (Table 2). Both yield single crystals suitable for X-ray analysis. Although the X-ray crystal structure of $\mathbf{1}$ was recently reported ${ }^{4)}$, the absolute configuration of the 16membered ring was established by spectral arguments relating tylosin to leucomycin ${ }^{5)}$.

Table 1. Physicochemical properties of tylactone (1), 5-O-mycarosyltylactone (2), 9-hydroxy-6,8-dimethylundeca-4,6-diene-3-one (4) and its $O$-benzoyl derivative (5).

\begin{tabular}{|c|c|c|c|c|}
\hline Compound & 1 & 2 & 4 & 5 \\
\hline Formula & $\mathrm{C}_{23} \mathrm{H}_{38} \mathrm{O}_{5}$ & $\mathrm{C}_{30} \mathrm{H}_{50} \mathrm{O}_{8}$ & $\mathrm{C}_{13} \mathrm{H}_{22} \mathrm{O}_{2}$ & $\mathrm{C}_{20} \mathrm{H}_{26} \mathrm{O}_{3}$ \\
\hline Parent $m / z$ & 394 (FDMS) & 538 (FDMS) & 210 (FIMS) & 314 (FDMS) \\
\hline M.P. (C) & $163 \sim 164.5$ & $182 \sim 184$ & oil & wax \\
\hline$[\alpha]_{\mathrm{D}}^{25}(\mathrm{MeOH})$ & $-56.0^{\circ}(c 6.0)$ & $-46.4^{\circ}(c 4.4)$ & -a) & - $^{\text {a) }}$ \\
\hline $\mathrm{UV} \lambda_{\text {mas: }}^{95 \% \text { EtOH }} \mathrm{nm}(\varepsilon)$ & $282(21,600)$ & $282(21,300)$ & $279(14,100)$ & $\begin{array}{l}276(14,800) \\
229(17,800)\end{array}$ \\
\hline IR $2 \mathrm{CO} \mathrm{cm}^{-1}\left(\mathrm{CHCl}_{3}\right)$ & 1713,1678 & 1715,1678 & 1710 & 1707 \\
\hline $\mathrm{Rf}$ & $0.22^{\mathrm{b})}$ & $0.15^{\mathrm{b})}$ & $0.35^{\mathrm{c})}$ & $0.62^{\mathrm{e})}$ \\
\hline
\end{tabular}

a) Insufficient material available.

b) Silica gel plates (E. Merck), developed in chloroform - ethyl acetate, 3: 1.

c) Silica gel plates (E. Merck), developed in toluene - acetone, 5: 1 . 
Table 2. The $360 \mathrm{MHz}{ }^{1} \mathrm{H} \mathrm{NMR}$ (in $\mathrm{CDCl}_{3}$ ) data for tylactone (1), 5-O-mycarosyltylactone (2), 9-hydroxy6,8-dimethylundeca-4,6-diene-3-one (4) and its $O$-benzoyl derivative (5).

For comparison purposes, the atoms in all four compounds are numbered below as in Fig. 1.

\begin{tabular}{|c|c|c|c|c|}
\hline \multirow{2}{*}{$\begin{array}{l}\text { Protons (s) } \\
\text { on atom }\end{array}$} & \multicolumn{4}{|c|}{ Shift $(\delta)$} \\
\hline & 1 & 2 & 4 & 5 \\
\hline $\begin{array}{ll}\mathrm{C} & 2 \\
\mathrm{C} & 3 \\
\mathrm{C} & 4\end{array}$ & $\begin{array}{c}2.48 / 1.93 \\
3.71 \\
1.47\end{array}$ & $\begin{array}{c}2.47 / 1.93 \\
3.68 \\
\sim 1.58\end{array}$ & & \\
\hline $\begin{array}{ll}\mathrm{C} & 5 \\
\mathrm{C} & 6 \\
\mathrm{C} & 7\end{array}$ & $\begin{array}{c}3.75 \\
1.55 / \text {-a) }^{\text {a) }}\end{array}$ & $\begin{aligned} & 3.76 \\
& \sim 1.58 \\
& \sim 1.58 / \sim 1.58\end{aligned}$ & & \\
\hline $\begin{array}{lr}\mathrm{C} & 8 \\
\mathrm{C} & 10 \\
\mathrm{C} & 11\end{array}$ & $\begin{array}{l}2.69 \\
6.31 \\
7.30\end{array}$ & $\begin{array}{l}2.75 \\
6.26 \\
7.32\end{array}$ & $\begin{array}{l}2.61 \\
6.12 \\
7.22\end{array}$ & $\begin{array}{l}2.62 \\
6.13 \\
7.12\end{array}$ \\
\hline $\begin{array}{ll}\mathrm{C} & 13 \\
\mathrm{C} & 14 \\
\mathrm{C} & 15\end{array}$ & $\begin{array}{l}5.64 \\
2.77 \\
4.70\end{array}$ & $\begin{array}{l}5.64 \\
2.71 \\
4.70\end{array}$ & $\begin{array}{l}5.90 \\
2.69 \\
3.44\end{array}$ & $\begin{array}{l}5.93 \\
2.98 \\
5.08\end{array}$ \\
\hline $\begin{array}{ll}\mathrm{C} & 16 \\
\mathrm{C} & 17 \\
\mathrm{C} & 18\end{array}$ & $\begin{array}{c}1.85 / \sim 1.61 \\
0.93 \\
0.99\end{array}$ & $\begin{array}{c}1.84 / \sim 1.58 \\
0.93 \\
0.93\end{array}$ & $\begin{array}{c}1.53 / 1.42 \\
0.96\end{array}$ & $\begin{array}{c}1.71 / 1.66 \\
0.94\end{array}$ \\
\hline $\begin{array}{ll}\mathrm{C} & 19 \\
\mathrm{C} & 20 \\
\mathrm{C} & 21\end{array}$ & $\begin{array}{r}\sim 1.61 \\
0.91 \\
1.22\end{array}$ & $\begin{array}{r}\sim 1.58 \\
\sim 0.93 \\
\\
1.21\end{array}$ & 1.12 & 1.13 \\
\hline $\begin{array}{lr}\mathrm{C} & 22 \\
\mathrm{C} & 23 \\
\mathrm{C} & 1^{\prime}\end{array}$ & $\begin{array}{l}1.82 \\
1.08\end{array}$ & $\begin{array}{l}1.79 \\
1.07 \\
4.85\end{array}$ & $\begin{array}{l}1.82 \\
1.05\end{array}$ & $\begin{array}{l}1.85 \\
1.08\end{array}$ \\
\hline $\begin{array}{ll}\mathrm{C} & 2^{\prime} \\
\mathrm{C} & 4^{\prime} \\
\mathrm{C} & 5^{\prime}\end{array}$ & & $\begin{array}{c}2.15 / 1.80 \\
2.96 \\
3.73\end{array}$ & & \\
\hline $\begin{array}{ll}\mathrm{C} & 6^{\prime} \\
\mathrm{C} & 7^{\prime}\end{array}$ & & $\begin{array}{l}1.29 \\
1.25\end{array}$ & & \\
\hline $\begin{array}{l}\mathrm{O} \quad 4^{\prime} \\
\text { Hydroxyl }\end{array}$ & $3.36^{a)}$ & $\begin{array}{l}2.14 \\
3.14^{a)} \\
\left.3.99^{a}\right)\end{array}$ & & \\
\hline Benzoyl & & & & $\begin{array}{l}7.50(3 \mathrm{H}) \\
8.13(2 \mathrm{H})\end{array}$ \\
\hline
\end{tabular}

a) Not assigned

We now report the X-ray crystal structure of 5-O-mycarosyltylactone, which unequivocally proves the absolute configuration of the lactone ring, since the absolute configuration of $\mathrm{L}-(-)$-mycarose has been previously determined ${ }^{\theta)}$. Fig. 1 (a) is an ORTEP drawing of the structure in the crystal, showing that the lactone ring has the same absolute configuration and a very similar conformation to that found in protylonolide (tylactone) $)^{4}$. In Fig. 1 (b), the molecule has been rotated $90^{\circ}$ about the vertical axis of the drawing, showing the three pseudo-axial oxygen atoms which protrude on the same face of the rather planar, but staggered, lactone ring.

Acidic hydrolysis of $\mathbf{2}$ yielded L-( - -)-mycarose ${ }^{7)}$, identical in all respects to a sample of mycarose obtained from acidic hydrolysis of tylosin. The other hydrolysis product was (-)-tylactone, identical in all respects to a sample which was efficiently bioconverted to tylosin by $t y l G$ mutants of $S$. fradia $e^{1,8)}$. Thus, the absolute configuration of both tylactone and tylosin (3) can be rigorously defined on the basis of the crystal structure of $\mathbf{2}$.

During the course of our work on the production of 5-O-mycarosyltylactone, one fermentation became contaminated by an unidentified bacterium. Upon workup of the broth from this fermentation, a new product was observed in addition to $\mathbf{1}$ and $\mathbf{2}$ (TLC analysis, visualization by ultraviolet light). 
Fig. 1. ORTEP plots of 5-O-mycarosyltylactone (a) with lactone ring oriented as in ŌMURA et al. ${ }^{4)}$, (b) rotated $90^{\circ}$ around vertical axis of drawing.

The thermal ellipsoids are drawn at the $50 \%$ probability level.

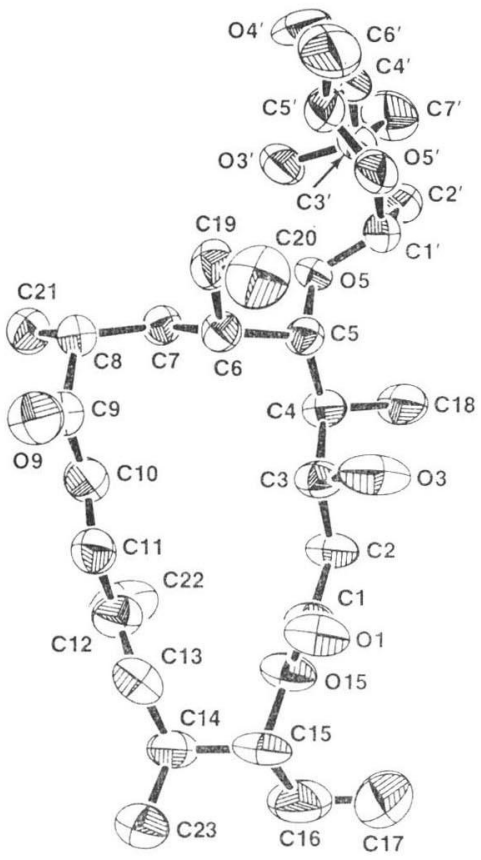

(a)

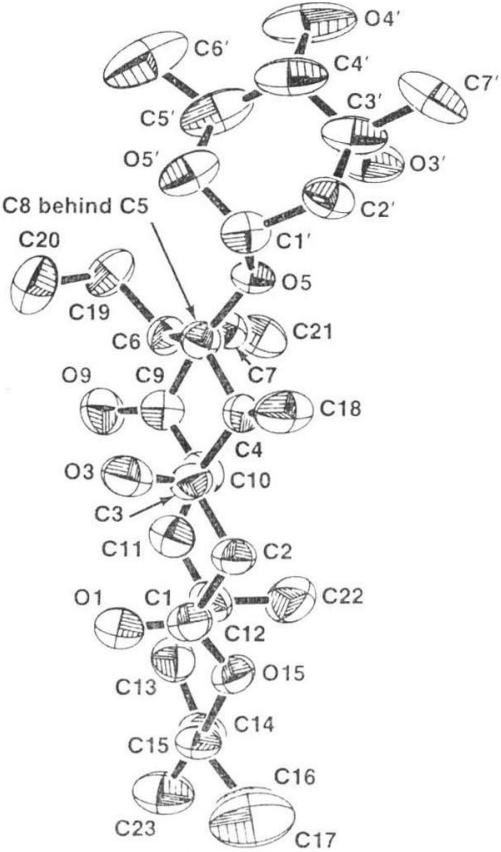

(b)

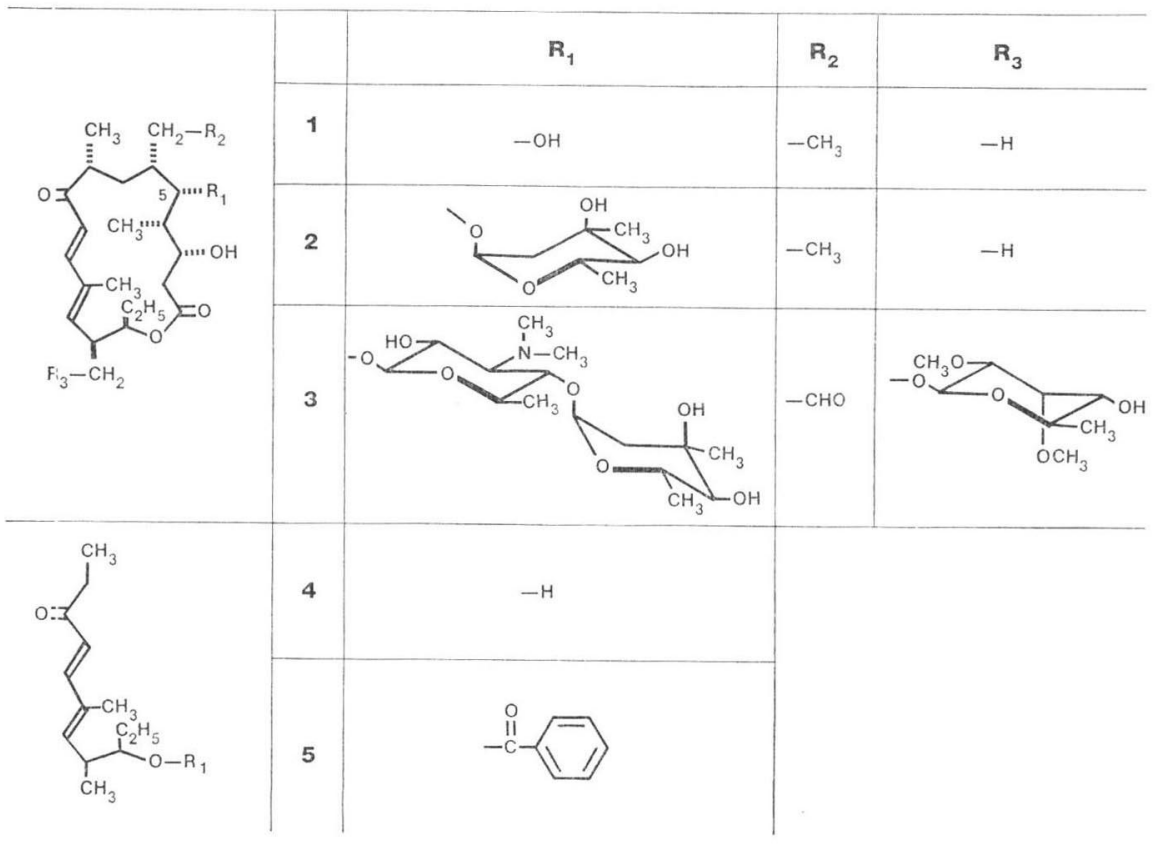


This new compound was less polar than either $\mathbf{1}$ or $\mathbf{2}$ and was readily separated from them by chromatography on silica gel. It was identified as 9-hydroxy-6,8-dimethylundeca-4,6-dien-3-one (4) on the basis of physicochemical data for it and its O-benzoyl derivative (5) (Tables 1 and 2). This new compound was clearly a fragment of tylactone, corresponding to carbon atoms 8 to 15 (with substituents) of tylactone. Since 4 was not observed in an uncontaminated fermentation, it most likely resulted from microbial degradation of tylactone*. Microbial degradation products of macrolide rings have not been previously identified ${ }^{11)}$, but microorganisms which can specifically degrade macrolide rings should be obtainable by routine screening procedures.

\section{Experimental}

Production and Isolation of Tylactone (1) and 5-O-Mycarosyltylactone (2)

A lyophilized pellet of Streptomyces fradiae GS-50 ${ }^{1)}$ dispersed in $1 \sim 2 \mathrm{ml}$ water was inoculated into $150 \mathrm{ml}$ of complex vegetative medium ${ }^{1)}$. Six $\mathrm{ml}$ portions of the vegetative culture were transferred to several $86 \mathrm{ml}$ volumes of complex fermentation media ${ }^{1)}$ in $500-\mathrm{ml}$ Erlenmeyer flasks and incubated in a closed box shaker at $29^{\circ} \mathrm{C}$ for 6 days at $300 \mathrm{rpm}$.

The pooled fermentation broth $(\sim 900 \mathrm{ml})$ obtained above was extracted with $900 \mathrm{ml}$ of petroleum ether and the extract was concentrated to an oil. The oil was dissolved in $15 \mathrm{ml}$ ethyl acetate, $15 \sim$ $20 \mathrm{ml}$ heptane was added, and the ethyl acetate was allowed to slowly evaporate to permit crystallization. The crystals were filtered and dried to yield $450 \mathrm{mg}$ of a mixture of 5-O-mycarosyltylactone and tylactone. The crystals $(400 \mathrm{mg}$ ) were dissolved in benzene and applied to a silica gel (Woelm) column packed in benzene. The elution was monitored by silica gel TLC using a benzene - ethyl acetate ( $3: 2)$ system and conc. sulfuric acid spray for detection. The column was eluted sequentially with 1 liter benzene, 1 liter benzene - ethyl acetate (9:1), 1.4 liter benzene - ethyl acetate (6:1), and 0.9 liter benzene - ethyl acetate (3:1) collecting $150 \mathrm{ml}$ fractions. Tylactone was eluted in fractions $14 \sim 19$ and then 5-O-mycarosyltylactone in fractions $22 \sim 26$. The fractions containing each were combined, evaporated in vacuo and crystallized from heptane. Analysis of tylactone: C $69.82 \%, \mathrm{H} 9.75 \%$, calcd. C $70.02 \%, \mathrm{H} 9.71 \%$. Analysis of 5-O-mycarosyltylactone: C $67.06 \%, \mathrm{H} 9.60 \%$, calcd. C $66.88 \%, \mathrm{H} 9.36 \%$.

Crystal Structure of 5-O-Mycarosyltylactone (2)

5-O-Mycarosyltylactone was recrystallized from heptane containing a small amount of ethyl acetate to obtain crystals suitable for X-ray crystal structure analysis. The compound forms yellowish prisms in the space group $\mathrm{P} 2_{1}$, with two molecules in a unit cell having the dimensions $a=14,986 \pm 0.006 \AA$, $b=15.797 \pm 0.004, c=6.820 \pm 0.001$ and $\beta=102.20 \pm 0.02^{\circ}$. The density determined by the flotation method was $1.12 \mathrm{~g} / \mathrm{cm}^{3}$, while that calculated for $\mathrm{C}_{30} \mathrm{H}_{50} \mathrm{O}_{8}$ (mol. wt. 538.7) is $1.13 \mathrm{~g} / \mathrm{cm}^{3}$. The intensities of 2262 independent reflections were measured on a four-circle, computer automated diffractometer, using monochromatic copper $\mathrm{K} \alpha$-radiation. The structure was solved using the direct methods program MULTAN-78 and was refined by the least-squares method to an R index of 0.069. In the final refinement cycle, all carbon and oxygen atoms had anisotropic temperature factors and all hydrogen atoms, except the three on oxygen, were included with isotropic temperature factors at assumed positions. The final non-hydrogen atom coordinates and their standard deviations are given in Table 3. The atoms are numbered as in Fig. 1.

Hydrolysis of 5-O-Mycarosyltylactone (2)

5-O-Mycarosyltylactone $(0.8 \mathrm{~g})$ was dissolved in methanol $(50 \mathrm{ml})$ and the solution was treated with $1 \mathrm{~N} \mathrm{HCl}(1 \mathrm{ml})$ and heated at $60^{\circ} \mathrm{C}$ for one hour. The solution was cooled to room temperature and adjusted to $\mathrm{pH} 11$ with $1 \mathrm{~N} \mathrm{NaOH}$. The solvent was evaporated under reduced pressure and the residue was partitioned between water and ethyl acetate. The aqueous layer was lyophilized and the organic

* An alternative explanation for 4 is microbially induced release and subsequent decarboxylation of a partially assembled polyketide chain from the enzyme complex of the $S$. fradiae mutant which normally produces tylactone. 
Table 3. Atomic coordinates (standard deviations) $\times 10^{4}$ for 5 - $O$-mycarosyltylactone.

\begin{tabular}{|c|c|c|c|c|c|c|c|c|}
\hline \multicolumn{2}{|c|}{ Atom } & \multirow{2}{*}{$\begin{array}{c}x \\
3075(6)\end{array}$} & \multirow{2}{*}{$\frac{y}{-2132(6)}$} & \multirow{2}{*}{$\frac{\mathrm{z}}{-3679(14)}$} & \multirow{2}{*}{$\begin{array}{l}\text { Atom } \\
\text { C } 20\end{array}$} & \multirow{2}{*}{$\frac{x}{-15(10)}$} & \multirow{2}{*}{$\begin{array}{c}y \\
891(9)\end{array}$} & \multirow{2}{*}{$\frac{\mathrm{z}}{-3499(18}$} \\
\hline $\mathrm{C}$ & 1 & & & & & & & \\
\hline $\mathrm{C}$ & 2 & $2331(6)$ & $-2295(6)$ & $-2621(14)$ & C 21 & $2515(8)$ & $689(8)$ & 4374 (14) \\
\hline $\mathrm{C}$ & 3 & $1669(6)$ & $-1545(6)$ & $-2705(12)$ & C 22 & $4558(10)$ & $-1494(11)$ & 1359 (16) \\
\hline $\mathrm{C}$ & 4 & $1042(6)$ & $-1630(5)$ & $-1246(12)$ & C 23 & $6096(7)$ & $-1664(10)$ & -3285 (19) \\
\hline $\mathrm{C}$ & 5 & $433(5)$ & -866 ( 5) & $-1209(11)$ & O 1 & $2980(4)$ & -1708 ( 6) & $-5230(10)$ \\
\hline $\mathrm{C}$ & 6 & $930(5)$ & $-12(5)$ & $-660(11)$ & $\mathrm{O}$ & $1121(5)$ & -1448 ( 6) & $-4684(10)$ \\
\hline $\mathrm{C}$ & 7 & $1407(5)$ & $8(5)$ & $1585(11)$ & $\mathrm{O}$ & $-156(3)$ & $-1011(4)$ & $185(7)$ \\
\hline $\mathrm{C}$ & 8 & $2068(6)$ & $754(6)$ & $2180(13)$ & $\mathrm{O}$ & $2892(5)$ & $1363(5)$ & $-92(11)$ \\
\hline $\mathrm{C}$ & 9 & $2809(6)$ & $762(6)$ & 914 (12) & O 15 & $3810(4)$ & $-2541(4)$ & -2898 ( 9) \\
\hline $\mathrm{C}$ & 10 & $3370(6)$ & $8(7)$ & $982(12)$ & C 1' & $-1060(5)$ & $-1250(5)$ & $-686(13)$ \\
\hline C & 11 & $3912(6)$ & $-144(7)$ & $-347(13)$ & $2^{\prime}$ & $-1423(6)$ & -1818 ( 6) & $822(14)$ \\
\hline $\mathrm{C}$ & 12 & $4467(6)$ & $-896(8)$ & $-341(12)$ & $3^{\prime}$ & $-1674(6)$ & -1392 ( 8) & 2537 (14) \\
\hline $\mathrm{C}$ & 13 & $4809(6)$ & $-1050(7)$ & $-1930(13)$ & $4^{\prime}$ & $-2256(6)$ & -635 ( 9) & $1884(17)$ \\
\hline $\mathrm{C}$ & 14 & $5299(6)$ & $-1842(7)$ & $-2357(13)$ & $5^{\prime}$ & $-1841(7)$ & $-78(7)$ & 557 (19) \\
\hline $\mathrm{C}$ & 15 & $4632(6)$ & $-2438(7)$ & $-3777(16)$ & $6^{\prime}$ & $-2456(12)$ & $630(10)$ & $-441(45)$ \\
\hline $\mathrm{C}$ & 16 & $5010(10)$ & $-3341(10)$ & $-3774(27)$ & $7^{\prime}$ & $-2158(8)$ & $-2015(11)$ & $3716(18)$ \\
\hline $\mathrm{C}$ & 17 & $4381(11)$ & $-3948(13)$ & $-5004(25)$ & $3^{\prime}$ & $-873(4)$ & $-1072(6)$ & $3952(10)$ \\
\hline $\mathrm{C}$ & 18 & $484(7)$ & $-2462(6)$ & $-1624(19)$ & $4^{\prime}$ & $-2424(6)$ & $-141(8)$ & 3472 (16) \\
\hline $\mathrm{C}$ & 19 & $290(7)$ & 747 ( 6) & $-1198(15)$ & $5^{\prime}$ & $-1635(4)$ & $-539 \quad(5)$ & $-1240(11)$ \\
\hline
\end{tabular}

Absolute configuration is represented by the right-hand coordinate system.

layer was dried over $\mathrm{Na}_{2} \mathrm{SO}_{4}$.

The residue from lyophilization was dissolved in $2 \mathrm{ml}$ of water and passed through a column of Dowex $50 \mathrm{~W}-\mathrm{X} 8\left(25 \mathrm{ml}, \mathrm{H}^{+}\right.$cycle). The column was eluted with water $(75 \mathrm{ml})$, the eluate was adjusted to $\mathrm{pH} 1.4$ with $1 \mathrm{~N} \mathrm{HCl}$ and the solution was allowed to stand at room temperature for 3 days. The solution was then concentrated to about $10 \mathrm{ml}$ under reduced pressure and passed through a column of BioRad AG1-X8 (50 ml, $\mathrm{OH}^{-}$cycle). The column was eluted with $150 \mathrm{ml}$ of water and the eluate was lyophilized to yield $66 \mathrm{mg}$ of mycarose. The material was crystallized from $\mathrm{CHCl}_{3}$ in the manner described by WOODWARD ${ }^{9}$, yielding crystalline mycarose identical in all respects (melting point, optical rotation, proton NMR and TLC mobility) to an authentic sample of mycarose obtained from the hydrolysis of tylosin in an analogous manner.

The dried ethyl acetate solution was filtered and the filtrate was evaporated under reduced pressure. The oily residue was dissolved in a small volume of toluene and purified by flash chromatography ${ }^{10)}$ on silica gel (E. Merck, grade 60). The column was eluted with a linear gradient of toluene $(500 \mathrm{ml})$ and toluene - ethyl acetate, $4: 1(500 \mathrm{ml})$, followed by an additional $250 \mathrm{ml}$ of the latter solvent. Fractions containing tylactone were located by TLC analysis and appropriate fractions were combined and evaporated to clryness to yield $360 \mathrm{mg}$ of product. Tylactone was crystallized by dissolving it in a small volume of ethyl acetate, diluting the solution with heptane and evaporating the ethyl acetate by warming on a steam bath. The sample of tylactone thus obtained was identical in all respects (melting point, optical rotation, proton NMR, TLC mobility and IR and UV spectra) to samples of tylactone isolated from wild type or $t y l A$ or $t y l B$ mutants of $S$. fradiae which have been bioconverted to tylosin by $t y l G$ mutants of 5. fradiae $^{1,8)}$.

Isolation of 9-Hydroxy-6,8-dimethylundeca-4,6-diene-3-one (4) and Its $O$-Benzoyl Derivative (5)

A sample of crude 9-hydroxy-6,8-dimethylundeca-4,6-diene-3-one, obtained as a byproduct of workup of a fermentation broth as described above, was further purified by chromatography on silica gel, eluting with a linear gradient of toluene and toluene-acetone, 3:1. Fractions containing the desired product were located by TLC analysis, combined and evaporated to dryness to yield $457 \mathrm{mg}$ of 
a yellow oil. A small sample (about $30 \mathrm{mg}$ ) was used to obtain physicochemical data and the remainder was dissolved in $10 \mathrm{ml}$ pyridine and treated with benzoic anhydride and a catalytic amount of dimethylaminopyridine $(10 \mathrm{mg})$ overnight at room temperature. After evaporation of solvent under reduced pressure, the residue was purified by flash chromatography on silica gel (E. Merck, grade 60), eluting with a linear gradient of $600 \mathrm{ml}$ toluene and $600 \mathrm{ml}$ of toluene - ethyl acetate, 5: 1. Fractions containing the desired product were located by TLC analysis, combined and evaporated to dryness to yield benzoate $\mathbf{5}$.

\section{References}

1) Baltz, R. H. \& E. T. Seno: Properties of Streptomyces fradiae mutants blocked in the biosynthesis of the macrolide antibiotic tylosin. Antimicrob. Agents Chemother. 20: 214 225, 1981

2) ŌmuRA, S.; C. Kitao \& H. Matsubara: Isolation and characterization of a new 16-membered lactone, protylonolide, from a mutant of tylosin-producing strain, Streptomyces fradiae KA-427. Chem. Pharm. Bull. 28: 1963 1965, 1980

3) Ōmura, S.; N. Sadakane, C. Kitao, H. Matsubara \& A. Nakagawa: Production of mycarosyl protylonolide by a mycaminose idiotroph from the tylosin-producing strain Streptomyces fradiae KA-427. J. Antibiotics 33: 913 914, 1980

4) Ōmura, S.; H. Matsubara, A. Nakagawa, A. Furusaki \& T. Matsumoto: X-Ray crystallography of protylonolide and absolute configuration of tylosin. J. Antibiotics 33: 915 917, 1980

5) Ōmura, S.; A. Nakagawa, M. Machida \& H. Imai: Evidence for configurational identity between leucomycin and tylosin. Tetrahedron Lett. 1977: 1045 1047, 1977

6) Foster, A. B.; T. D. Inch, J. Lehmann, L. F. Thomas, J. M. Webber \& J. A. Wyer: The absolute configuration of mycarose. Proc. Chem. Soc. 1962: 254, 1962

7) Regna, P. P.; F. A. Hochstein, R. L. Wagner, Jr. \& R. B. Woodward: Magnamycin. II. Mycarose, an unusual branched-chain desoxysugar from magnamycin. J. Am. Chem. Soc. 75: 4625 4626, 1953

8) Baltz, R. H.; E. T. Seno, J. Stonesifer, P. Matsushima \& G. M. Wild: Genetics and biochemistry of tylosin production by Streptomyces fradiae. In "Microbiology-1981", Ed., D. SCHLESSINGER, pp. 371 375, American Society for Microbiology, Washington, DC, 1981

9) Lemal, D. M.; P. D. PAChT \& R. B. Woodward: The synthesis of L-(-)-mycarose and L-(-)-cladinose. Tetrahedron 18: 1275 1293, 1962

10) StiLl, W. C.; M. KAHN \& A. Mitra: Rapid chromatographic technique for preparative separations with moderate resolution. J. Org. Chem. 43: 2923 2925, 1978

11) Flickinger, M. C. \& D. Perlman: Microbial degradation of erythromycins A and B. J. Antibiotics 28: $307 \sim 311,1975$ 